Research article

\title{
Alternative use of multiple exons 1 of aromatase gene in cancerous and normal breast tissues from women over the age of 80 years
}

\author{
Naoko Honma1, Kaiyo Takubo1, Motoji Sawabe², Tomio Arai², Futoshi Akiyama ${ }^{3}$, Goi Sakamoto ${ }^{3}$, \\ Toshiaki Utsumi ${ }^{4}$, Noriko Yoshimura ${ }^{5}$ and Nobuhiro Harada ${ }^{5}$
}

\begin{abstract}
${ }^{1}$ Research Team for Geriatric Diseases, Tokyo Metropolitan Institute of Gerontology, Sakaecho 35-2, Itabashi-ku, Tokyo 173-0015, Japan 2Department of Pathology, Tokyo Metropolitan Geriatric Medical Center, Sakaecho 35-2, Itabashi-ku, Tokyo 173-0015, Japan ${ }^{3}$ Department of Breast Pathology, Cancer Institute, Ariake 3-10-6, Koto-ku, Tokyo 135-8550, Japan

${ }^{4}$ Department of Surgery, Fujita Health University School of Medicine, Dengakugakubo 1-98, Kutsukake-cho, Toyoake, Aichi 470-1192, Japan ${ }^{5}$ Department of Biochemistry, Fujita Health University School of Medicine, Dengakugakubo 1-98, Kutsukake-cho, Toyoake, Aichi 470-1192, Japan

Corresponding author: Naoko Honma,nhonma@tmig.or.jp
\end{abstract}

Received: 23 Jan 2009 Revisions requested: 25 Feb 2009 Revisions received: 1 Jun 2009 Accepted: 10 Jul 2009 Published: 10 Jul 2009

Breast Cancer Research 2009, 11:R48 (doi:10.1186/bcr2335)

This article is online at: http://breast-cancer-research.com/content/11/4/R48

(c) 2009 Honma et al.; licensee BioMed Central Ltd.

This is an open access article distributed under the terms of the Creative Commons Attribution License (http://creativecommons.org/licenses/by/2.0), which permits unrestricted use, distribution, and reproduction in any medium, provided the original work is properly cited.

\begin{abstract}
Introduction Peripherally localized aromatase, which converts circulating androgens into estrogens, is important in the pathogenesis of postmenopausal breast carcinomas. We have previously shown that aromatase mRNA levels are higher in elderly breast carcinomas (EldCa) than breast carcinomas of the control group (ContCa) or normal breast tissues. Aromatase expression has been reported to be regulated through the alternative use of multiple exons 1 (exons $1 \mathrm{a}-1 \mathrm{f}$ and so on); however, the preferential usage of exons 1 in elderly breast tissue has never been systematically examined. In order to properly treat and protect against $\mathrm{EldCa}$, the regulation mechanism of aromatase expression in elderly breast tissues should be elucidated. The aim of the present study is to elucidate whether there are any specific patterns in use of multiple exons 1 in elderly breast tissue.
\end{abstract}

Methods Usage of multiple exons 1 of the aromatase gene and mRNA levels of aromatase were examined by reverse transcription-polymerase chain reaction analysis in breast tissues of 38 elderly patients with breast cancer (age 80-99), and the results were compared with those in 35 patients of the control group (age 37-70). One-factor analysis of variance and the Scheffé test were used for the comparison of aromatase mRNA levels. Patterns of preferential utilization of multiple exons 1 of the aromatase gene were compared by $\chi^{2}$ test for independence or Fisher exact test for independence using a contingency table.

Results Exon 1d was utilized much more frequently in elderly tissue than in the control group irrespective of cancerous or normal tissue (EldCa, 36/38, 95\% versus ContCa, 7/35, 20\%, $P<0.0001$; normal tissue of the elderly, EldNorm, 30/34, $88 \%$ versus normal tissue of controls, ContNorm, 2/29, 7\%, $P<$ 0.0001). Twenty EldCa (53\%) and 12 EldNorm (35\%) used both exons $1 \mathrm{c}$ and $1 \mathrm{~d}$; however, their dominance was reversed (EldCa, all 1d > 1c; EldNorm, all 1c > 1d).

Conclusions Elderly breast tissues exhibited specific patterns in use of multiple exons 1 , which at least partly explained the higher aromatase levels in EldCa. The mechanisms of how these specific patterns occur during aging and carcinogenesis should be further examined.

\section{Introduction}

Estrogen plays important roles in the pathogenesis and development of breast cancer [1]. In postmenopausal women, in whom ovarian function has decreased, the peripheral metabo- lism and biosynthesis of estrogens via estrogen-metabolizing enzymes are important. Among several estrogen-metabolizing enzymes involved in the pathogenesis of breast cancer [2-10], aromatase is a key enzyme, converting circulating androgens

ANOVA: analysis of variance; ContCa: carcinomas from controls; ContNorm: normal tissues from controls; COUP-TF-1: chicken ovalbumin upstream promoter-transcription factor 1; COX-2: cyclooxygenase-2; CRE: cAMP-responsive element; EldCa: carcinomas from the elderly; EldNorm: normal tissues from the elderly; ER: estrogen receptor; Ex 1: multiple exons 1 of the aromatase gene; PCR: polymerase chain reaction; $P G E_{2}$ : prostaglandin $\mathrm{E}_{2}$; RT: reverse transcription; RT-PCR: reverse transcription-polymerase chain reaction; S1: silencer element. 
from the adrenal gland or ovary into estrogens [2]. The application of aromatase inhibitors is already a standardized treatment for postmenopausal breast carcinomas [11-14].

Physiologically, aromatase exists not only in gonadal tissues such as the ovary and placenta, but also in extragonadal tissues such as the brain [15], skin fibroblasts [16], and adipose tissue [17]. The tissue-specific expression of aromatase is strictly regulated; however, it is difficult to explain the complex transcriptional regulation of the aromatase gene in various tissues by a single gene and a single promoter. Multiple tissuespecific promoters of the aromatase gene were first shown by Means and colleagues [18] and Mahendroo and colleagues [19]. We reported that the aromatase gene was regulated tissue-specifically through the alternative use of multiple exons 1 [20]. Exons 1a (I.1), 1b (I.4), 1c (I.3), and 1d (P.II) are used mainly for aromatase mRNAs of the placenta, skin fibroblast/ fetal liver, ovary, and prostate/ovary, respectively. Each of the multiple exons 1 of the human aromatase gene is flanked by a unique promoter region [21]. In regard to breast carcinogenesis, switching of the preferential utilization of multiple exons 1 , exon $1 \mathrm{~b}$ to exon $1 \mathrm{c} / 1 \mathrm{~d}$, has been suggested to be responsible for the abnormal expression of aromatase and consequent overproduction of local estrogen in tumors $[22,23]$.

Breast carcinoma in very elderly women is of interest because ovarian estrogens are markedly low throughout the disease process. A previous study revealed that breast carcinoma in very elderly women exhibits a distinct histologic pattern and hormone receptor status [24]. We have examined mRNA levels of several estrogen-metabolizing enzymes and have shown that levels of aromatase mRNA were significantly higher in breast carcinomas from women over the age of 80 years than in carcinomas from younger women or in normal breast tissues [25]. These findings suggest that breast carcinomas in very elderly women are quite different from those in younger women in terms of aromatase expression. As aromatase expression is regulated by multiple exons 1 of the aromatase gene, this should be elucidated in order to provide proper treatment or protect against breast carcinomas in very elderly women. In the present study, we investigate the preferential utilization of multiple exons 1 of the aromatase gene, which has never been systematically examined in breast carcinomas or normal tissues of the elderly, and compare it with that in breast tissues from younger women.

\section{Materials and methods Patients}

Materials for this study were obtained from 38 Japanese patients over the age of 80 (range 80 to 99 and mean 86) years and 35 Japanese patients ages 37 to 70 (mean 53) years with primary breast carcinomas who underwent curative surgery at the Tokyo Metropolitan Geriatric Medical Center and Fujita Health University Hospital, respectively, between 1999 and 2003. All tumors were histologically classified by pathologists (NHo, KT, and GS) according to the World Health Organization classification [26]. Of the 38 carcinomas of the elderly, 24, 7, 5, and 2 were classified as invasive ductal carcinoma, apocrine carcinoma, mucinous carcinoma, and invasive lobular carcinoma, respectively, whereas all 35 carcinomas of the younger group were classified as invasive ductal carcinoma. Immediately after surgical removal, the specimens of both tumor tissues and normal tissues were frozen in liquid nitrogen and then stored at $-80^{\circ} \mathrm{C}$ prior to use. Normal breast tissues were available in 34 elderly and 29 control cases. Materials were classified into four tissue categories: carcinomas from the elderly (EldCa), normal tissues from the elderly (EldNorm), carcinomas from controls (ContCa), and normal tissues from controls (ContNorm). Informed consent was obtained, and the study protocol was approved by the Tokyo Metropolitan Institute of Gerontology Ethics Committee.

\section{Quantification of aromatase mRNA}

Frozen tissues were homogenized as previously reported [7], and total RNA fractions were prepared from homogenates as described by Chirgwin and colleagues [27]. Quantitative analysis of aromatase mRNA in RNA fractions was carried out by reverse transcription-polymerase chain reaction (RT-PCR) using a fluorescent primer in the presence of an internal standard RNA, as previously described $[28,29]$. Oligonucleotides of antisense primer 6a (5'-AACCACGATAGCACTTTCGT-3' specific for exon 6) for RT and antisense (5'-TGTTAGAGGTGTCCAGCATG-3' specific for exon 6) and sense (5'-TACTACAACCGGGTATATGG-3' specific for exon 3) primers $6 \mathrm{~b}$ and $3 a$ for PCR were synthesized. The sense primer $3 a$ for PCR was labeled with a fluorescent dye, 6-carboxyfluorescein (PerkinElmer, Waltham, MA, USA). To prepare the internal standard RNA, modified human aromatase cDNA was constructed by inserting a 21-base pair DNA fragment between the two PCR primer sites. The internal standard RNA was synthesized in vitro with T7 RNA polymerase using modified aromatase cDNA as a template. Total RNA mixed with a known amount of internal standard RNA was subjected to RT with SuperScript II RNase H- Reverse Transcriptase (Invitrogen Corporation, Carlsbad, CA, USA) and specific antisense primer $6 \mathrm{a}$ at $42^{\circ} \mathrm{C}$ for 40 minutes. The resulting cDNAs were amplified by PCR using fluorescence-labeled primers $3 a$ and $6 \mathrm{~b}$. The fluorescent PCR products were electrophoresed in a $2 \%$ agarose gel and analyzed with an ABI PRISM 377 DNA Sequencer (Applied Biosystems, Foster City, CA, USA). The amount of aromatase mRNA was calculated from the peak areas of fluorescent products by the internal standard method.

\section{Analysis of alternative usage of exons 1 in aromatase mRNA}

The utilization of multiple exons 1 of the aromatase gene in breast tissues was investigated by RT-PCR as previously described [28]. Oligonucleotide primers 1a (5'-CTGGAGGGCTGAACACGTGG-3'), specific for placenta-type exon 1 (exon 1a); 1b (5'-GACCAACTGGAGCCTGACAG-3'), spe- 
cific for skin fibroblast/fetal liver-type exon 1 (exon 1b); 1c (5'CCTTGTTTTGACTTGTAACCA-3'), specific for ovary-type exon 1 (exon 1c); and 1d (5'-AACAGGAGCTATAGATGAAC$\left.3^{\prime}\right)$, specific for ovary/prostate-type exon 1 (exon 1d), and antisense primer 3b (5'-CAGAGATCCAGACTCGCATG-3'), specific for exon 3 , were synthesized.

RNA fractions from breast tissues were reverse-transcribed with SuperScript II RNase $\mathrm{H}^{-}$Reverse Transcriptase and specific antisense primer $6 a$. The resulting cDNAs were amplified by PCR using fluorescent dye (6-carboxyfluorescein)-labeled primer $3 \mathrm{~b}$ and primer $1 \mathrm{a}, 1 \mathrm{~b}, 1 \mathrm{c}$, or $1 \mathrm{~d}$. Fluorescent PCR products were separated by electrophoresis on a $2 \%$ agarose gel and then analyzed with an ABI PRISM 377 DNA Sequencer.

\section{Immunohistochemistry}

Representative slides of primary carcinomas were selected for immunohistochemical examination. Antigen retrieval was performed by boiling the sections for 2 minutes in $10 \mathrm{mM}$ citrate buffer ( $\mathrm{pH} \mathrm{6)}$ using a pressure cooker. After the blocking of nonspecific activity, the sections were incubated with prediluted anti-estrogen receptor (anti-ER) mouse monoclonal antibody (clone 1D5; Dako, Carpinteria, CA, USA). Incubation with the anti-ER antibody was for 60 minutes at room temperature. Dako ChemMate Envision (Dako) was used for all immunohistochemical stains. A positive control slide, whose immunoreactivity had been confirmed, and a negative control slide, to which subclass-matched control lgGs instead of the specific monoclonal antibody were applied, were included in each batch. The results of immunologic staining were assessed by two pathologists (NHo and KT) independently, and where discrepancies occurred, the cases were discussed. Immunoreactivity for ER was scored by evaluating the percentage of positively stained cancer cells, irrespective of intensity; nuclear immunoreactivity in $10 \%$ or more of the cancer cells was considered positive according to St. Gallen Consensus 2003 [30].

\section{Statistics}

Statistical analyses were carried out using StatView 5.0 (SAS Institute Inc., Cary, NC, USA). In regard to aromatase mRNA levels, one-factor analysis of variance (ANOVA) was used for the comparison of multiple groups, and the Scheffé test was used for comparisons between two of the multiple groups. For comparison of aromatase mRNA levels between mucinous carcinomas and carcinomas of other histologic types, the Student $t$ test was used. Patterns of preferential utilization of multiple exons 1 of the aromatase gene (or distribution of 'Ex 1 group' as described below) were compared by chi-square test for independence or Fisher exact test for independence using a contingency table as follows: EldCa versus EldNorm, ContCa versus ContNorm, EldCa versus ContCa, and EldNorm versus ContNorm. A $P$ value of less than 0.05 was considered significant.

\section{Results Comparison of aromatase mRNA levels among each tissue category}

Levels of the mean \pm standard error of mean of aromatase mRNA obtained for EldCa, EldNorm, ContCa, and ContNorm were $19.7 \pm 2.97 \mathrm{amol} / \mathrm{mgRNA}, 8.22 \pm 1.91 \mathrm{amol} / \mathrm{mgRNA}$, $9.45 \pm 1.75 \mathrm{amol} / \mathrm{mgRNA}$, and $4.26 \pm 1.09 \mathrm{amol} / \mathrm{mgRNA}$, respectively (Table 1 and Figure 1). Aromatase mRNA levels were significantly different among the four tissue categories (one-factor ANOVA, $P<0.0001$ ). When cancerous and normal tissues were compared, EldCa exhibited significantly higher aromatase levels than did EldNorm (Scheffé test, $P=$ 0.0028 ), whereas there was no significant difference between ContCa and ContNorm $(P=0.4477)$. When the elderly and controls were compared, EldCa exhibited significantly higher aromatase levels than did ContCa $(P=0.0095)$, whereas there was no significant difference between EldNorm and ContNorm $(P=0.6760)$ (Figure 1).

\section{Comparison of preferential utilization of multiple exons 1 of the aromatase gene and aromatase mRNA levels among EldCa, EldNorm, ContCa, and ContNorm}

To determine which types of multiple exons 1 are used, RTPCR analysis was carried out, and the relative utilization preference of exons 1 was fluorometrically determined as shown in Figure 2. Utilization of multiple exons 1 in each tissue category (EldCa, EldNorm, ContCa, and ContNorm) and mean levels of aromatase mRNA according to which exons 1 were used are summarized in Table 1. In the first column of Table 1, for example, exon $1 d>1 b>1 c$ is conventionally designated as dbc. The proportion of cases utilizing exon $1 \mathrm{c}$ and/or $1 \mathrm{~d}$ was higher in ContCa $(26 / 35=74 \%)$ than in ContNorm (16/ $29=55 \%$ ), although the difference was not significant (chisquare test for independence, $P=0.1090)$. Most of both EldCa $(36 / 38=95 \%)$ and EldNorm $(30 / 34=88 \%)$ utilized exon $1 \mathrm{~d}$, whereas a significantly lower proportion of ContCa $(7 / 35=20 \%)$ and ContNorm $(2 / 29=7 \%)$ utilized exon 1d (Fisher exact test for independence, EldCa versus ContCa, $P$ $<0.0001$; EldNorm versus ContNorm, $P<0.0001$ ). In both EldCa and EldNorm, cases that utilized both exon $1 \mathrm{c}$ and exon $1 \mathrm{~d}$ exhibited higher aromatase mRNA levels than those utilizing either exon $1 \mathrm{c}$ or exon $1 \mathrm{~d}$. Furthermore, among EldCa and EldNorm utilizing both exon $1 \mathrm{c}$ and exon $1 \mathrm{~d}$, all of EldCa exhibited exon $1 \mathrm{~d}>$ exon 1c, whereas EldNorm exhibited the opposite result. Given the characteristic pattern of exon 1 utilization among each tissue category and aromatase mRNA levels, cases were categorized into five groups according to which exons 1 were utilized (Ex 1 groups): group 'b', which exclusively utilized exon $1 \mathrm{~b}$; group ' $\mathrm{c}$ ', which utilized exon $1 \mathrm{c}$ but not exon $1 \mathrm{~d}$; group ' $c>d$ ', which utilized both exon $1 \mathrm{c}$ and exon $1 \mathrm{~d}$ with dominance of exon 1c; group ' $d$ ', which utilized exon $1 \mathrm{~d}$ but not exon 1c; and group ' $\mathrm{d}>\mathrm{c}$ ', which utilized both exon $1 \mathrm{c}$ and exon $1 \mathrm{~d}$ with dominance of exon $1 \mathrm{~d}$. The presence or dominance of exon $1 \mathrm{~b}$ did not affect aromatase mRNA levels when co-utilized with other exons 1 , and grouping was regard- 
Table 1

Aromatase mRNA levels and preferential utilization of multiple exons 1 of the aromatase gene

\begin{tabular}{|c|c|c|c|c|c|c|c|c|c|}
\hline \multirow[t]{3}{*}{ Exon 1 group } & \multicolumn{8}{|c|}{ Tissue category } & \multirow{3}{*}{$P$ value } \\
\hline & \multicolumn{2}{|c|}{ EldCa } & \multicolumn{2}{|c|}{ EldNorm } & \multicolumn{2}{|c|}{ ContCa } & \multicolumn{2}{|c|}{ ContNorm } & \\
\hline & n (\%) & $\begin{array}{c}\text { Aromatase } \\
\text { mRNA } \pm \\
\text { SEM }^{\mathrm{b}}\end{array}$ & n (\%) & $\begin{array}{c}\text { Aromatase } \\
\text { mRNA } \pm \\
\text { SEM }^{\mathrm{b}}\end{array}$ & n (\%) & $\begin{array}{c}\text { Aromatase } \\
\text { mRNA } \pm \\
\text { SEM }^{\mathrm{b}}\end{array}$ & n (\%) & $\begin{array}{c}\text { Aromatase } \\
\text { mRNA } \pm \\
\text { SEM }^{\mathrm{b}}\end{array}$ & \\
\hline 'd > c' & $20(53 \%)$ & $26.5 \pm 4.49$ & & & $1(3 \%)$ & 22.8 & & & $0.8610 \mathrm{NS}$ \\
\hline $\mathrm{dc}$ & $5(13 \%)$ & $35.5 \pm 14.4$ & & & & & & & \\
\hline dcb & $1(3 \%)$ & 18.8 & & & & & & & \\
\hline $\mathrm{dbc}$ & $7(18 \%)$ & $21.8 \pm 5.79$ & & & & & & & \\
\hline bdc & $7(18 \%)$ & $25.8 \pm 5.98$ & & & $1(3 \%)$ & 22.8 & & & \\
\hline 'd' & $16(42 \%)$ & $12.0 \pm 3.28$ & $18(53 \%)$ & $4.67 \pm 1.13$ & $2(6 \%)$ & $10.9 \pm 7.75$ & & & $0.0941 \mathrm{NS}$ \\
\hline$d$ & $12(32 \%)$ & $13.7 \pm 4.21$ & $15(44 \%)$ & $4.13 \pm 1.30$ & & & & & \\
\hline $\mathrm{db}$ & $2(5 \%)$ & $6.05 \pm 0.350$ & $1(3 \%)$ & 9.20 & & & & & \\
\hline bd & $2(5 \%)$ & $8.25 \pm 7.15$ & $2(6 \%)$ & $6.45 \pm 0.950$ & $2(6 \%)$ & $10.9 \pm 7.75$ & & & \\
\hline 'c $>d$ ' & & & $12(35 \%)$ & $15.3 \pm 4.54$ & $4(11 \%)$ & $8.56 \pm 4.57$ & $2(7 \%)$ & $2.98 \pm 1.67$ & 0.4445 NS \\
\hline $\mathrm{cd}$ & & & $1(3 \%)$ & 10.5 & $3(9 \%)$ & $4.44 \pm 2.80$ & $2(7 \%)$ & $2.98 \pm 1.67$ & \\
\hline $\mathrm{cdb}$ & & & $3(9 \%)$ & $11.2 \pm 9.32$ & & & & & \\
\hline $\mathrm{cbd}$ & & & 5 (15\%) & $20.5 \pm 8.85$ & $1(3 \%)$ & 20.9 & & & \\
\hline bcd & & & $3(9 \%)$ & $12.6 \pm 8.18$ & & & & & \\
\hline 'c' & $2(5 \%)$ & $13.1 \pm 11.6$ & $3(9 \%)$ & $3.37 \pm 2.56$ & 19 (54\%) & $10.8 \pm 2.82$ & $14(48 \%)$ & $7.26 \pm 1.96$ & $0.5534 \mathrm{NS}$ \\
\hline $\mathrm{c}$ & $2(5 \%)$ & $13.1 \pm 11.6$ & $3(9 \%)$ & $3.37 \pm 2.56$ & $10(29 \%)$ & $9.07 \pm 4.34$ & $5(17 \%)$ & $2.04 \pm 0.645$ & \\
\hline $\mathrm{cb}$ & & & & & $4(11 \%)$ & $17.2 \pm 7.01$ & $5(17 \%)$ & $9.33 \pm 3.54$ & \\
\hline bc & & & & & $5(14 \%)$ & $9.12 \pm 3.30$ & $4(14 \%)$ & $11.2 \pm 4.26$ & \\
\hline 'b' = b & & & $1(3 \%)$ & 1.10 & $9(26 \%)$ & $5.21 \pm 1.54$ & $13(45 \%)$ & $1.22 \pm 0.339$ & $0.0222 \mathrm{~S}$ \\
\hline Total & $38(100 \%)$ & $19.7 \pm 2.97$ & $34(100 \%)$ & $8.22 \pm 1.91$ & 35 (100\%) & $9.45 \pm 1.75$ & $29(100 \%)$ & $4.26 \pm 1.09$ & $<0.0001 \mathrm{~S}$ \\
\hline$P$ value $c$ & 0.05 & $11 \mathrm{NS}$ & 0.0 & $444 \mathrm{~S}$ & 0.48 & 71 NS & 0.0 & $209 \mathrm{~S}$ & \\
\hline
\end{tabular}

Comparison of aromatase mRNA levels according to preferential utilization of multiple exons 1 of the aromatase gene in carcinomas from the elderly (EldCa), normal tissues from the elderly (EldNorm), carcinomas from controls (ContCa), and normal tissues from controls (ContNorm). For example, dcb means exon $1 \mathrm{~d}>1 \mathrm{c}>1 \mathrm{~b}$. aComparison of aromatase mRNA levels according to tissue categories in each exon 1 group or in total (one-factor analysis of variance). bValues are presented in amol/mgRNA. ' Comparison of aromatase mRNA levels according to exon $1 \mathrm{groups}$ in each tissue category (one-factor analysis of variance). NS, not significant; S, significant; SEM, standard error of the mean.

less of exon $1 b$; for example, cases showing exon $1 d>1 c$, exon $1 d>1 c>1 b$, exon $1 d>1 b>1 c$, and exon $1 b>1 d>$ $1 c$ were all categorized into group ' $d>c$ ' (Table 1). The distribution of Ex 1 groups was significantly different between EldCa and EldNorm, between EldCa and ContCa, and between EldNorm and ContNorm (all $P<0.0001$, chi-square test for independence), whereas there was no significant difference between ContCa and ContNorm $(P=0.3274)$ (Figure 1).
Comparison of aromatase mRNA levels according to Ex 1 groups in each tissue category or according to tissue categories in each Ex 1 group

Significant or almost significant differences in aromatase mRNA levels according to Ex 1 groups were observed in EldCa $(P=0.0511)$, EldNorm $(P=0.0444)$, and ContNorm $(P=0.0209)$, whereas no significant difference was obtained in ContCa $(P=0.4871$, one-factor ANOVA) (Table 1). There was no significant difference of aromatase mRNA levels according to tissue categories in each Ex 1 group except group 'b' (group 'd $>$ c', $P=0.8610$; group 'd', $P=0.0941$; 
Figure 1

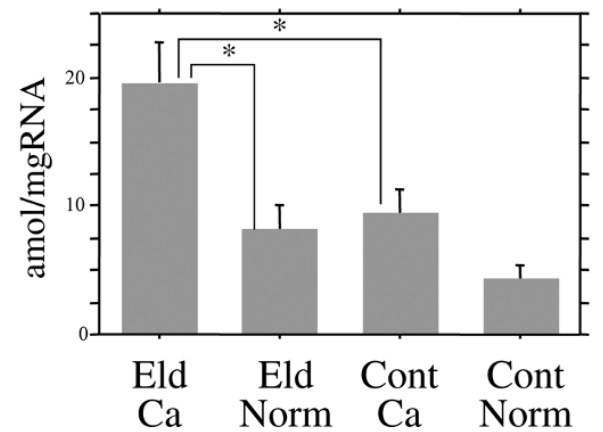

Ex1 group

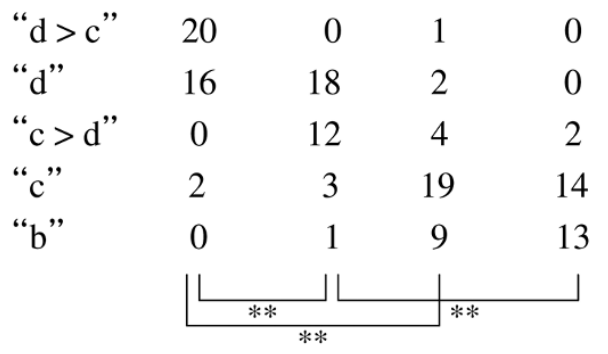

Comparison of aromatase mRNA levels and distribution of Ex 1 groups among tissue categories. Aromatase mRNA levels (top, Scheffé test) and distribution of Ex 1 groups (bottom, chi-square test for independence) were compared among carcinomas from the elderly (EldCa), normal tissues from the elderly (EldNorm), carcinomas from controls (ContCa), and normal tissues from controls (ContNorm). Bar indicates standard error of the mean. ${ }^{\star} P<0.01 ;{ }^{*} P<0.0001$.

Figure 2

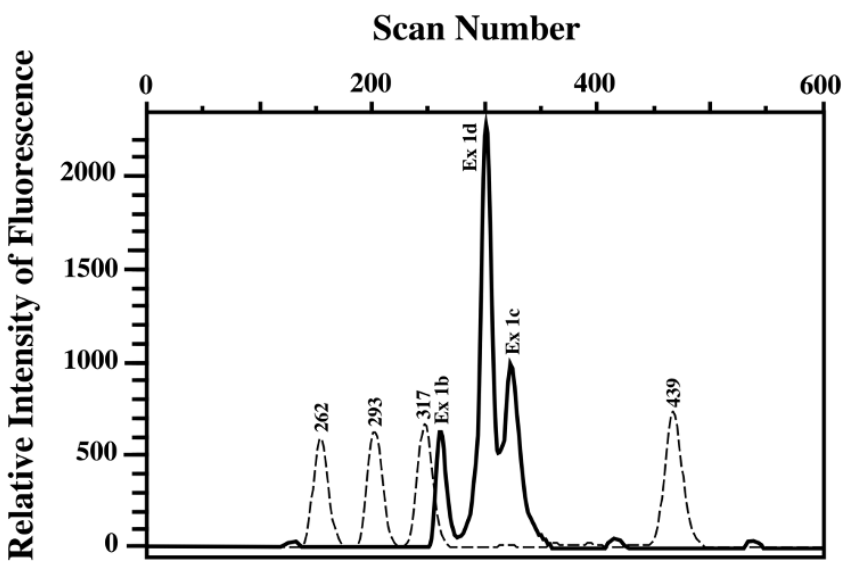

Reverse transcription-polymerase chain reaction analysis of usage of alternative exons 1 of the aromatase gene. An example of a breast cancer from elderly patients $(E l d C a)$ is shown. Exon $1 \mathrm{~d}$ is preferentially used in the EldCa case, followed by exon $1 \mathrm{c}$ and exon $1 \mathrm{~b}(1 \mathrm{~d}>1 \mathrm{c}>$ $1 \mathrm{~b}, \mathrm{dcb}$, unbroken line). Broken line indicates size standards. group 'c $>$ d', $P=0.4445$; group 'c', $P=0.5534$; group 'b', $P$ $=0.0222 ;$ one-factor ANOVA) (Table 1$)$.

\section{Comparison of estrogen receptor status, aromatase mRNA levels, and distribution of Ex 1 groups according to histologic types among EldCa}

Mean levels of aromatase mRNA were compared according to histologic types among EldCa (Table 2). Significant difference of aromatase levels was observed among the four histologic types ( $P=0.0403$, one-factor ANOVA). Mucinous carcinomas exhibited significantly higher levels than the other carcinomas (39.1 $\pm 8.99 \mathrm{amol} / \mathrm{mgRNA}$ versus $16.8 \pm 2.86 \mathrm{amol} / \mathrm{mgRNA}$, $P=0.0090$, Student $t$ test). All five mucinous carcinomas were ER-positive (Table 2). In regard to the distribution of Ex 1 groups in each histologic type (Table 2), all five mucinous carcinomas were classified as group ' $d>c$ ', showing a tendency to differ from the distribution of the other carcinomas $(P$ $=0.0750$, chi-square test for independence).

\section{Discussion}

EldCa, EldNorm, ContCa, and ContNorm each exhibited characteristic features in the usage of multiple exons 1 of the aromatase gene. The distribution of Ex 1 groups was significantly different between EldCa and EldNorm, between EldCa and ContCa, and between EldNorm and ContNorm (all $P<$ $0.0001)$. Mean levels of aromatase mRNA were significantly different among the four tissue categories $(P<0.0001)$, producing significant differences between EldCa and EldNorm and between EldCa and ContCa. Aromatase mRNA levels significantly or almost significantly differed according to Ex 1 groups in each tissue category except ContCa, whereas no significant difference of aromatase mRNA levels was observed according to tissue categories in any Ex 1 group except group 'b'. Those results suggest that differences of aromatase mRNA levels between tissue categories were related to the preferential usage of multiple exons 1 in each tissue category (Figure 1).

Given that exon 1d was used in a significantly larger proportion of elderly tissues than the tissues of the control group regardless of whether the tissue was cancerous or normal, the utilization of exon $1 \mathrm{~d}$ seems to be characteristic of elderly tissue. Contrary to the control group, where exon $1 \mathrm{~b}$ is preferentially utilized under physiologic conditions, the utilization of exon $1 \mathrm{~d}$ seems to be physiologic in the elderly. The specific utilization pattern of multiple exons 1 in elderly breast tissue has not been reported elsewhere. This seems to be because of a difference in subjects as the present study dealt with a number of tissues in the very elderly, who have been free from ovarian function for decades and in whom peripherally localized estrogen-metabolizing enzymes are almost the sole source of estrogens. Among many estrogen-metabolizing enzymes, aromatase plays a key role in estrogen biosynthesis. Estrogen is known to be essential to maintain various physiologic functions. The decrease of serum estrogens has been 
Table 2

Estrogen receptor status, aromatase mRNA levels, and exon 1 group of cancer from the elderly according to histologic types

\begin{tabular}{|c|c|c|c|c|c|c|c|c|}
\hline \multirow[t]{2}{*}{ Histologic type (n) } & \multicolumn{2}{|c|}{ Estrogen receptor } & \multirow[t]{2}{*}{ Aromatase $\mathrm{mRNA} \pm \mathrm{SEM}$, amol/mgRNA } & \multicolumn{5}{|c|}{ Exon 1 group } \\
\hline & $+(\%)$ & - & & $d>c$ & $d$ & $c<d$ & c & $b$ \\
\hline Muc (5) & $5(100 \%)$ & 0 & $39.1 \pm 8.99$ & 5 & 0 & 0 & 0 & 0 \\
\hline Others (33) & $22(67 \%)$ & 11 & $16.8 \pm 2.86$ & 15 & 16 & 0 & 2 & 0 \\
\hline Apo (7) & $0(0 \%)$ & 7 & $20.1 \pm 4.06$ & 3 & 3 & 0 & 1 & 0 \\
\hline ILC (2) & $1(50 \%)$ & 1 & $2.45 \pm 0.05$ & 1 & 1 & 0 & 0 & 0 \\
\hline IDC (24) & $21(88 \%)$ & 3 & $17.0 \pm 3.68$ & 11 & 12 & 0 & 1 & 0 \\
\hline Total (38) & $27(71 \%)$ & 11 & $19.7 \pm 2.97$ & 20 & 16 & 0 & 2 & 0 \\
\hline$P$ value Muc vs. others & & & $0.0090 \mathrm{~S}$ & $0.0750 \mathrm{NS}$ & & & & \\
\hline
\end{tabular}

+, positive; -, negative; Apo, apocrine carcinoma; IDC, invasive ductal carcinoma; ILC, invasive lobular carcinoma; Muc, mucinous carcinoma; NS, not significant; S, significant; SEM, standard error of the mean.

reported to be related to many geriatric diseases, including osteoporosis [31], Alzheimer disease [32], and atherosclerosis [33]. Although aromatase mRNA levels of EldNorm and ContNorm did not significantly differ, EldNorm exhibited almost twice the levels of aromatase mRNA in comparison with ContNorm. Switching of the preferential use of multiple exons 1 during aging might be advantageous to peripherally produce estrogens by increasing aromatase levels (Figure 1). Given that connective tissue is a major component of normal breast tissue, it cannot be excluded that such phenomena may be observed systemically. Several authors have reported that basal aromatase levels in peripheral stroma are increased in the elderly [34-36]. A systematic study may elucidate the physiologic role of aromatase in the elderly.

Contrary to EldNorm, among which more than $30 \%$ of cases were classified as group ' $c>d$ ', more than half of cases of EldCa were classified as group ' $d>c$ '. The precise mechanisms of how exon $1 \mathrm{~d}$ becomes frequently utilized among elderly tissues and how the dominance of exon $1 \mathrm{~d}$ and exon $1 \mathrm{c}$ is converted between EldCa and EldNorm are not known at present. Each exon 1 has its characteristic promoter region [21]. The promoter of exon $1 \mathrm{~b}$, a glucocorticoid-stimulated promoter, has a characteristic TATA box-less and GC-box structure, which is often found in the proximal regions of housekeeping genes, and is regulated by class 1 cytokines, tumor necrosis factor-alpha, and glucocorticoids. This may be why transcription from exon $1 \mathrm{~b}$ does not seem to be so rigid and is widely found in extragonadal tissues, such as skin fibroblasts, adipose tissue, and normal breast tissue. The promoters of exons $1 \mathrm{c} / 1 \mathrm{~d}$, in contrast, have not only the rigid structure of CAAT and TATA boxes but also multiple sites of activator protein-1 and CAMP-responsive element (CRE) in proximal regions which enable induction of the effective transcription of the aromatase gene in response to various stimulants, such as prostaglandin $\mathrm{E}_{2}\left(\mathrm{PGE}_{2}\right)$, gonadotropins, or growth factors, whose second messenger is cAMP or protein kinase C (PKC) [21]. During senescence, upregulated cyclooxygenase-2 (COX-2) expression and the resulting increase in the production of $\mathrm{PGE}_{2}$ in stromal cells, such as fibroblasts or macrophages, have been reported [37-39]. Interaction between carcinoma cells and surrounding stromal cells also elevates COX-2 and $\mathrm{PGE}_{2}$ levels [40]. $\mathrm{PGE}_{2}$ may be one of the key factors to explain the switching mechanism from exon $1 \mathrm{~b}$ to exon $1 \mathrm{c} / 1 \mathrm{~d}$ during aging and carcinogenesis $[22,41]$. Gonadotropins may be another candidate to explain the mechanism. Markedly low serum estrogen levels in elderly women result in the elevation of gonadotropins, which may lead to switching to exon $1 \mathrm{c} / 1 \mathrm{~d}$ through cAMP. cAMP will activate PKA, which will lead to the binding of CRE binding (CREB) to CRE in proximal region of exons 1c/1d. Exons $1 \mathrm{c} /$ $d$ are typically utilized in the ovary, where aromatase is induced in response to gonadotropins [20]. Our preliminary study suggested that the ovary may alternatively utilize exon $1 \mathrm{c}$ or $1 \mathrm{~d}$ according to the menstrual cycle (unpublished observation). Changes in hormonal circumstances, such as the ratio of gonadotropins (follicle-stimulating hormone/lutenizing hormone) during the menstrual cycle, may be somehow associated with the switching between exon $1 \mathrm{c}$ and $1 \mathrm{~d}$. In cancerous tissue, there have been many studies to elucidate the DNAbinding proteins, transcription factors, and co-regulators that regulate the alternative utilization of multiple exons $1[42,43]$. For example, S1 (silencer element), which is situated between exons $1 \mathrm{c}$ and $1 \mathrm{~d}$, negatively regulates aromatase expression in normal breast tissue, suppressing the function of exons $1 \mathrm{c} / 1 \mathrm{~d}$ in combination with EAR-2/COUP-TF-1/EAR- $\gamma$. In cancer tissue, the expression levels of EAR-2/COUP-TF-1/EAR- $\gamma$ decreased and aromatase expression is upregulated through the binding of ERR $\alpha-1$ (estrogen-related receptor alpha-1) to S1 [42,43]. Aging and carcinogenesis may somehow affect the constitution of these DNA-binding proteins, transcription factors, and co-regulators. Further study is needed to eluci- 
date the molecular mechanism of switching of the preferential use of multiple exons 1 during aging and carcinogenesis.

Among EldCa, mucinous carcinomas examined were all ERpositive $[44,45]$, were all classified as group ' $d>c$ ', and exhibited significantly higher aromatase mRNA levels than other carcinomas. These findings may suggest the importance of peripheral aromatase and estrogens in the pathobiology of mucinous carcinoma, which is a specific histologic type frequently observed in elderly women [24].

\section{Conclusions}

This is the first study to systematically examine the preferential usage of multiple exons 1 of the aromatase gene in breast tissue of the very elderly. Elderly breast tissues typically used exon $1 \mathrm{~d}$ irrespective of whether the tissues were cancerous or normal. The dominance of exon $1 \mathrm{c}$ and exon $1 \mathrm{~d}$ was converted between cancerous and normal tissues. This seems to at least partly explain the elevation of aromatase mRNA levels in elderly breast cancer. The molecular mechanism of how switching of exons 1 occurs should be further studied.

\section{Competing interests}

The authors declare that they have no competing interests.

\section{Authors' contributions}

NHo designed the study, provided study materials, analyzed data, and drafted the manuscript. KT histologically classified breast carcinomas and scored the immunohistochemical results. MS, TA, FA, and TU provided study materials. GS histologically classified breast carcinomas. NY analyzed mRNA data. NHa designed the study, analyzed mRNA data, and helped to draft the manuscript. All authors read and approved the final manuscript.

\section{Acknowledgements}

This research was supported by JSPS KAKENHI 17590324 and 18591034.

\section{References}

1. Beatson GT: On the treatment of inoperable cases of carcinoma of the mamma: suggestions for a new method of treatment, with illustrative cases. Lancet 1896, ii:104-107.

2. Miller WR, Hawkins RA, Forrest AP: Significance of aromatase activity in human breast cancer. Cancer Res 1982, 42:3365s-3368s.

3. Santen RJ, Martel J, Hoagland M, Naftolin F, Roa L, Harada N, Hafer L, Zaino R, Santner SJ: Stromal spindle cells contain aromatase in human breast tumors. J Clin Endocrinol Metab 1994, 79:627-632.

4. Sasano H, Frost AR, Saitoh R, Harada N, Poutanen M, Vihko R, Bulun SE, Silverberg SG, Nagura H: Aromatase and 17 betahydroxysteroid dehydrogenase type 1 in human breast carcinoma. J Clin Endocrinol Metab 1996, 81:4042-4046.

5. Santner SJ, Feil PD, Santen RJ: In situ estrogen production via the estrone sulfatase pathway in breast tumors: relative importance versus the aromatase pathway. J Clin Endocrinol Metab 1984, 59:29-33.

6. Tseng L, Mazella J, Lee LY, Stone ML: Estrogen sulfatase and estrogen sulfotransferase in human primary mammary carcinoma. J Steroid Biochem 1983, 19:1413-1417.
7. Utsumi T, Yoshimura N, Takeuchi S, Ando J, Maruta M, Maeda K, Harada N: Steroid sulfatase expression is an independent predictor of recurrence in human breast cancer. Cancer Res 1999, 59:377-381.

8. Suzuki T, Nakata T, Miki Y, Kaneko C, Moriya T, Ishida T, Akinaga $S$, Hirakawa H, Kimura M, Sasano H: Estrogen sulfotransferase and steroid sulfatase in human breast carcinoma. Cancer Res 2003, 63:2762-2770.

9. Suzuki T, Moriya T, Ariga N, Kaneko C, Kanazawa M, Sasano H: 17Beta-hydroxysteroid dehydrogenase type 1 and type 2 in human breast carcinoma: a correlation to clinicopathological parameters. Br J Cancer 2000, 82:518-523.

10. Oduwole OO, Li Y, Isomaa VV, Mantyniemi A, Pulkka AE, Soini $Y$, Vihko PT: 17beta-hydroxysteroid dehydrogenase type 1 is an independent prognostic marker in breast cancer. Cancer Res 2004, 64:7604-7609.

11. Miller WR: Aromatase inhibitors in the treatment of advanced breast cancer. Cancer Treat Rev 1989, 16:83-93.

12. Buzdar A, Jonat W, Howell A, Jones SE, Blomqvist C, Vogel CL, Eiermann W, Wolter JM, Azab M, Webster A, Plourde PV: Anastrozole, a potent and selective aromatase inhibitor, versus megestrol acetate in postmenopausal women with advanced breast cancer: results of overview analysis of two phase III trials. Arimidex Study Group. J Clin Oncol 1996, 14:2000-2011.

13. Iveson TJ, Smith IE, Ahern J, Smithers DA, Trunet PF, Dowsett M: Phase I study of the oral nonsteroidal aromatase inhibitor CGS 20267 in postmenopausal patients with advanced breast cancer. Cancer Res 1993, 53:266-270.

14. Smith IE, Dowsett M: Aromatase inhibitors in breast cancer. $N$ Engl J Med 2003, 348:2431-2442.

15. Naftolin F, Ryan KJ, Petro Z: Aromatization of androstenedione by the anterior hypothalamus of adult male and female rats. Endocrinology 1972, 90:295-298.

16. Berkovitz GD, Bisat T, Carter KM: Aromatase activity in microsomal preparations of human genital skin fibroblasts: influence of glucocorticoids. J Steroid Biochem 1989, 33:341-347.

17. Schindler AE, Ebert A, Friedrich E: Conversion of androstenedione to estrone by human tissue. J Clin Endocrinol Metab 1972, 35:627-630

18. Means GD, Kilgore MW, Mahendroo MS, Mendelson CR, Simpson ER: Tissue-specific promoters regulate aromatase cytochrome P450 gene expression in human ovary and fetal tissues. Mol Endocrinol 1991, 5:2005-2013.

19. Mahendroo MS, Means GD, Mendelson CR, Simpson ER: Tissuespecific expression of human P-450AROM. The promoter responsible for expression in adipose tissue is different from that utilized in placenta. $J$ Biol Chem 1991, 266:11276-11281.

20. Harada N, Utsumi T, Takagi Y: Tissue-specific expression of the human aromatase cytochrome P-450 gene by alternative use of multiple exons 1 and promoters, and switching of tissuespecific exons 1 in carcinogenesis. Proc Natl Acad Sci USA 1993, 90:11312-11316.

21. Harada N: Aromatase and intracrinology of estrogen in hormone-dependent tumors. Oncology 1999, 57(Suppl 2):7-16.

22. Utsumi T, Harada N, Maruta M, Takagi Y: Presence of alternatively spliced transcripts of aromatase gene in human breast cancer. J Clin Endocrinol Metab 1996, 81:2344-2349.

23. Agarwal VR, Bulun SE, Leitch M, Rohrich R, Simpson ER: Use of alternative promoters to express the aromatase cytochrome P450 (CYP19) gene in breast adipose tissues of cancer-free and breast cancer patients. J Clin Endocrinol Metab 1996, 81:3843-3849.

24. Honma N, Sakamoto G, Akiyama F, Esaki Y, Sawabe M, Arai T, Hosoi T, Harada N, Younes M, Takubo K: Breast carcinoma in women over the age of 85: distinct histological pattern and androgen, oestrogen, and progesterone receptor status. His topathology 2003, 42:120-127.

25. Honma N, Takubo K, Sawabe M, Arai T, Akiyama F, Sakamoto G, Utsumi T, Yoshimura N, Harada N: Estrogen-metabolizing enzymes in breast cancers from women over the age of $\mathbf{8 0}$ years. J Clin Endocrinol Metab 2006, 91:607-613.

26. Tavassoli FA, Devilee P, Eds: Pathology and Genetics of Tumours of the Breast and Female Genital Organs Lyon, France: IARC Press; 2003.

27. Chirgwin JM, Przybyla AE, MacDonald RJ, Rutter WJ: Isolation of biologically active ribonucleic acid from sources enriched in ribonuclease. Biochemistry 1979, 18:5294-5299. 
28. Harada N: Aberrant expression of aromatase in breast cancer tissues. J Steroid Biochem Mol Biol 1997, 61:175-184.

29. Yoshimura N, Harada N, Bukholm I, Karesen R, Borresen-Dale AL, Kristensen VN: Intratumoural mRNA expression of genes from the oestradiol metabolic pathway and clinical and histopathological parameters of breast cancer. Breast Cancer Res 2004, 6:R46-55.

30. Goldhirsch A, Wood WC, Gelber RD, Coates AS, Thurlimann B, Senn HJ: Meeting highlights: updated international expert consensus on the primary therapy of early breast cancer. J Clin Oncol 2003, 21:3357-3365.

31. Weitzmann MN, Pacifici R: Estrogen deficiency and bone loss: an inflammatory tale. J Clin Invest 2006, 116:1186-1194.

32. Manly JJ, Merchant CA, Jacobs DM, Small SA, Bell K, Ferin M, Mayeux R: Endogenous estrogen levels and Alzheimer's disease among postmenopausal women. Neurology 2000, 54:833-837.

33. Ouyang $\mathrm{P}$, Michos ED, Karas RH: Hormone replacement therapy and the cardiovascular system lessons learned and unanswered questions. J Am Coll Cardiol 2006, 47:1741-1753.

34. Hemsell DL, Grodin JM, Brenner PF, Siiteri PK, MacDonald PC: Plasma precursors of estrogen. II. Correlation of the extent of conversion of plasma androstenedione to estrone with age. J Clin Endocrinol Metab 1974, 38:476-479.

35. Cleland WH, Mendelson CR, Simpson ER: Effects of aging and obesity on aromatase activity of human adipose cells. J Clin Endocrinol Metab 1985, 60:174-177.

36. Bulun SE, Simpson ER: Competitive reverse transcriptionpolymerase chain reaction analysis indicates that levels of aromatase cytochrome P450 transcripts in adipose tissue of buttocks, thighs, and abdomen of women increase with advancing age. J Clin Endocrinol Metab 1994, 78:428-432.

37. Mayahara K, Kobayashi Y, Takimoto K, Suzuki N, Mitsui N, Shimizu $\mathrm{N}$ : Aging stimulates cyclooxygenase-2 expression and prostaglandin E2 production in human periodontal ligament cells after the application of compressive force. J Periodontal Res 2007, 42:8-14.

38. Meydani SN, Wu D: Age-associated inflammatory changes: role of nutritional intervention. Nutr Rev 2007, 65:S213-216.

39. Zdanov S, Bernard D, Debacq-Chainiaux F, Martien S, Gosselin K, Vercamer C, Chelli F, Toussaint O, Abbadie C: Normal or stressinduced fibroblast senescence involves COX-2 activity. Exp Cell Res 2007, 313:3046-3056.

40. Davies G, Martin LA, Sacks N, Dowsett M: Cyclooxygenase-2 (COX-2), aromatase and breast cancer: a possible role for COX-2 inhibitors in breast cancer chemoprevention. Ann Oncol 2002, 13:669-678.

41. Bulun SE, Zeitoun K, Sasano H, Simpson ER: Aromatase in aging women. Semin Reprod Endocrinol 1999, 17:349-358.

42. Chen S, Ye J, Kijima I, Kinoshita Y, Zhou D: Positive and negative transcriptional regulation of aromatase expression in human breast cancer tissue. J Steroid Biochem Mol Biol 2005, 95:17-23.

43. Chen S, Zhou D, Okubo T, Kao YC, Yang C: Breast tumor aromatase: functional role and transcriptional regulation. Endocr Relat Cancer 1999, 6:149-156.

44. Shousha S, Coady AT, Stamp T, James KR, Alaghband-Zadeh J: Oestrogen receptors in mucinous carcinoma of the breast: an immunohistological study using paraffin wax sections. J Clin Pathol 1989, 42:902-905.

45. Diab SG, Clark GM, Osborne CK, Libby A, Allred DC, Elledge RM: Tumor characteristics and clinical outcome of tubular and mucinous breast carcinomas. J Clin Oncol 1999, 17:1442-1448. 